\title{
BMJ Open How common are neurocognitive disorders in patients with chronic kidney disease and diabetes? Results from a cross-sectional study in a community cohort of patients in North Wales, UK
}

Peter Hobson, ${ }^{1}$ Aled Lewis, ${ }^{2}$ Hari Nair, ${ }^{2}$ Stephen Wong, ${ }^{3}$ Mick Kumwenda ${ }^{2}$

To cite: Hobson P, Lewis A, Nair $\mathrm{H}$, et al. How common are neurocognitive disorders in patients with chronic kidney disease and diabetes? Results from a cross-sectional study in a community cohort of patients in North Wales, UK. BMJ Open 2018;8:e23520. doi:10.1136/ bmjopen-2018-023520

- Prepublication history and additional material for this paper are available online. To view these files, please visit the journal online (http://dx.doi. org/10.1136/bmjopen-2018023520).

Received 11 April 2018 Revised 16 August 2018 Accepted 11 October 2018

Check for updates

(C) Author(s) (or their employer(s)) 2018. Re-use permitted under CC BY-NC. No commercial re-use. See rights and permissions. Published by BMJ.

${ }^{1}$ Academic Unit, Glan Clwyd Hospital, Betsi Cadwaladr University Health Board, Rhyl, UK ${ }^{2}$ Department of Nephrology, Betsi Cadwaladr University Health Board, Rhyl, UK ${ }^{3}$ Department of Diabetes \& Endocrinology, Betsi Cadwaladr University Health Board, Rhyl, Denbighshire, UK

Correspondence to Dr Peter Hobson; peter.hobson@wales.nhs.uk

\section{ABSTRACT}

Objective Chronic kidney disease (CKD) affects nearly $9 \%$ of global populations and is strongly associated with older age. Neurocognitive disorders (NCDs), which include mild cognitive impairment and dementia, are rising as a result of ageing populations throughout the world. This investigation's aim is to report the frequency of mild to major NCD in a clinical cohort of adults with mild to moderate CKD and diabetes.

Setting Glan Clwyd District general Hospital, North Wales, UK.

Participants We enrolled 178 patients with CKD and diabetes, aged 55 years and over with an estimated glomerular filtration rate $<60>15 \mathrm{~mL} / \mathrm{min} / 1.73 \mathrm{~m}^{2}$, attending a specialist renal and diabetic outpatient clinic.

Outcome measures Frequency of mild and major NCD and the association with the stage of CKD was assessed in all patients attending the specialist clinic. The diagnosis of NCD was based on patient and informant interview, case note review, neuropsychological assessment and application of Diagnostic and Statistical Manual of Mental Disorders version 5 .

Results This investigation found 86/178 (48\%) of the cohort with an NCD ranging from mild $(n=49)$ to major symptoms $(n=37)$. No association was found with NCD and the stage of CKD. Mild and major NCD was associated poorer outcomes in several cognitive domains, including, language, executive, memory, fluency and attention function $(p<0.05)$.

Conclusions This is the first UK investigation to report that cognitive changes occur in a significant number of older adults with CKD and diabetes. The unexpected finding was that prior to cognitive assessment, not any of the cohort had a pre-existing diagnosis of cognitive impairment, suggesting that the current prevalence and incidence rates of NCD in the general population are possibly significantly underestimated. Our findings also suggest that the cognitive function of patients with CKD should be screened and monitored routinely as part of their overall care management.
Strengths and limitations of this study

- This is the first UK study to investigate the frequency of neurocognitive disorders in patients with mild to moderate chronic kidney disease and diabetes.

- All patients' neurocognitive function was formally evaluated by neuropsychological assessment and application of Diagnostic and Statistical Manual of Mental Disorders version 5 criteria.

- There was no neuroimaging to confirm or support cardiovascular diagnosis.

- This was a cross-sectional sample investigation.

\section{INTRODUCTION}

Nearly $9 \%$ of global populations are diagnosed with chronic kidney disease (CKD), which is strongly associated with older age and cardiovascular risks such as diabetes and hypertension. ${ }^{1-4}$ Cognitive impairment in CKD compared with general populations appears to occur quite frequently. ${ }^{5-10}$ The Intervention Project on Cerebrovascular Diseases and Dementia in the community of Ebersberg (INVADE) study reported a prevalence of cognitive impairment of around $21 \%$ in patients with CKD and the recent Brain in Kidney Disease (BRINK) cohort study investigation reported that overall cognitive impairment was significantly associated with the more advanced stages of CKD. ${ }^{11} 12$ Longitudinal investigations have suggested that there is at least a twofold increased risk of developing cognitive impairment in CKD compared with the general population. ${ }^{10}$ One British cohort investigation of patients with end-stage kidney disease (ESKD) reported a prevalence of cognitive impairment at baseline of around $68 \%$ and a 2.5 increased risk of mortality at follow-up. ${ }^{13}$ The wide variation 
of reported cognitive impairment in cross-sectional and longitudinal studies is most likely due to the methodological differences such as, inclusion of patients with ESKD alone; gender-specific investigations; samples drawn from at risk or elderly populations or from much larger population investigations. ${ }^{10}$ However, if patients with cognitive impairment are not recognised at an early stage of their disease journey, this will most likely impinge on their ability to make informed decisions about their current and future care, particularly as the symptoms of CKD progress and its management becomes more complex. Furthermore, identification of patients with CKD with cognitive impairment will also provide more accurate estimates for policy and healthcare planners.

Recent results from population investigations report a slowing in the incidence of dementia, which has been attributed to potentially earlier and more appropriate primary and secondary care interventions specifically targeted at risk population disorders, such as cardiovascular disease. ${ }^{14-18}$ Seven potentially modifiable risk factors have been identified including, mid-life obesity, mid-life diabetes mellitus, mid-life hypertension, physical inactivity, smoking, depression and lower educational attainment. It has been suggested that if reductions of between $10 \%$ and $25 \%$ in the above-mentioned risk factors were made at population level, it could result in the prevention of between 1 and 3 million cases of dementia worldwide. ${ }^{19}$ While modifiable lifestyle risk factors have been identified, there is still poor public awareness of the role they can play in prevention or slowing of cognitive impairment. ${ }^{20}$ In view of the established association with ageing, the associated cardiovascular disease risk and CKD, this is one condition where earlier therapeutic opportunities, interventions and management may delay or reduce the risk of individuals developing significant cognitive impairment.

There have not been any population at risk screening investigations for cognitive impairment in patients with established CKD in the UK. This study is the preliminary report from a longitudinal CKD observational cohort investigation in Denbighshire North Wales, UK, which aims first, to report the frequency of neurocognitive disorders (NCDs) ranging from no impairment to major impairment, in a cohort of older adults with mild to moderate CKD and concomitant diabetes attending a specialist renal outpatient's clinic. Second, to explore if the stage of renal impairment as measured by glomerular filtration rate (GFR) is independently associated with neurocognitive function. Lastly, this investigation will explore if there are associations with NCD, and demographic, clinical measures including several blood and urine biomarkers routinely measured in CKD, along with physical function, mood and quality of life.

\section{Subjects and methods}

Patients aged 55 years and over were recruited from an outpatient renal and diabetic clinic. All of the participants had an established diagnosis of CKD with an estimated
GFRs (eGFR based on The Modification of Diet in Renal Disease Study equation) of $<60 \mathrm{~mL} / \mathrm{min} / 1.73 \mathrm{~m}^{2}$ and confirmed diagnosis of diabetes mellitus. Subjects were excluded if they had previously had suffered a stroke, transient ischaemic attack (TIA), had severe sensory impairment, a significant neuropsychiatric disorder, ESKD (eGFR $<15 \mathrm{~mL} / \mathrm{min} / 1.73 \mathrm{~m}^{2}$ ), receiving renal replacement therapy, or if they were in receipt of a transplant.

Based on their eGFR ${ }^{21}$ at study entry, patients were grouped by stage of CKD as follows:

Stage 3a (G3a) - an eGFR of $45-59 \mathrm{~mL} / \mathrm{min}$.

Stage 3b (G3b) -an eGFR of $30-44 \mathrm{~mL} / \mathrm{min}$.

Stage 4 (G4) -an eGFR of $15-29 \mathrm{~mL} / \mathrm{min}$.

\section{Assessment and diagnosis of neurocognitive function}

Global cognitive function was assessed with the Addenbrooke's Cognitive Examination III (ACE III).$^{22}$ The ACE III assesses five cognitive domains: attention, memory, fluency, language, visuospatial abilities. The scoring the ACE III is a sum of the items for each of the five cognitive domains (attention total $=18$, memory total $=26$, fluency total $=14$, language total $=26$, visuospatial total $=16$ ), with a maximum of 100 points, where higher scores indicate better cognitive functioning. Scores of $<88$ are suggestive of cognitive impairment.

Executive function was assessed with the Weigl Colour Form Sorting Test (WCFST). ${ }^{23}$ The WCFST is made up of three geometric shapes, (square, circle, triangle), grouped into four colours (red, green, blue and yellow). Subjects are asked to 'sort the shapes', for example, to shape or colour and when they complete this they are instructed to sort the shapes in a different way. The scoring on the WCFT ranges from 0 to 4 where higher scores indicate better cognitive function.

The term dementia was replaced with major NCD on the introduction of Diagnostic and Statistical Manual of Mental Disorders version 5 (DSM-5) ${ }^{24}$ The aetiological subtype of the NCD is then specified, for example, Alzheimer's disease, vascular disease, Parkinson's disease, substance abuse, traumatic brain injury. The diagnosis of mild cognitive impairment (MCI) employing Peterson's criteria is now referred in DSM-5 as mild NCD. It is based on patients, caregivers, informants and or clinician-observed reports of symptoms of memory impairment, decline in the ability to perform everyday activities, difficulties with language, perceptual-motor and social skills, in the absence of delirium or dementia. ${ }^{2526}$

The diagnosis of an NCD in the current investigation was reached by consensus by all of the authors in this study, who also clinically manage all of the patients participating in the study. This was based on patient and informant review, clinical case review, neuropsychological assessment and application of DSM-5 criteria for NCDs. ${ }^{24}$ To meet this criterion, patients must present with significant deficits in one or more cognitive domains that cannot be explained by delirium or other mental disorder. All patients who met DSM-5 criteria for either a 
mild or a moderate NCD were signposted to appropriate memory clinic pathways.

In addition to the cognitive assessments, on the day of testing, demographic details, onset and duration of CKD, diabetes and hypertension, CKD stage, cholesterol, non-High-density lipoproteins (HDL)/HDL, Low-density lipoproteins (LDL), blood pressure, mood disorder with the nine item Patient Health Questionnaire (PHQ-9) and Health Related Quality of Life (HRQoL) was assessed with the EuroQol-5D (EQ-5D). ${ }^{27}{ }^{28}$ Anaemia was defined using WHO guidelines as haemoglobin $(\mathrm{Hb})$ in males $<130 \mathrm{~g} / \mathrm{dL}$ and $<120 \mathrm{~g} / \mathrm{L}$ in females. ${ }^{29}$

\section{Patient and public involvement}

Patients and or the public were not involved in the design of the study. However, participants on request will be sent a summary of the findings of the study.

\section{Statistical analysis}

The demographic characteristics of the patients, as well as their neuropsychological assessments were summarised with descriptive statistics including ratios, mean, SD $( \pm)$ and median. The normality of the data was inspected by employing the Shapiro-Wilk test and Levene's test. The continuous variables in this investigation were compared with the independent t-tests. The categorical variables in this investigation, for example, stage of CKD, were expressed as proportions and they were analysed employing the $\chi^{2}$ test.

The main outcomes in the current investigation were the occurrence of mild to major NCD (coded to DSM-5) and the stage of CKD (bases on eGFR staging). A one-way analysis of variance (ANOVA) was carried out on the individual cohort characteristics between the stages of CKD (3a, 3b, 4). Likewise a similar analysis was completed between the neurocognitive diagnosis of no cognitive impairment (NCI), mild and major NCD. To investigate between group differences post hoc Tukey's honestly significant difference was employed. Where the homogeneity of variances was observed to be violated (Leven's test), the non-parametric Games-Howell test was employed. The Mood's median test (non-parametric alternative to ANOVA) was employed where data were skewed or there was evidence of outliers. For the NCD and CKD outcomes, covariates were adjusted which included, demographics (age, education, gender), chronic conditions, including, ischaemic heart disease, hypertension, mood, blood pressure (systolic/diastolic), Hemoglobin A1c (HbA1c) and lipoprotein results. In addition, the covariates of kidney function eGFR, creatinine and urine albumin to creatinine ratio were adjusted for where appropriate.

To examine the associations between NCD and specific cognitive domains, multiple regression was performed employing a binary logistic model. The variables in this model were explored with backward Wald likelihood ratio logistic regression analysis modelling with adjustment for age, gender, education, hypertension and mood. The
Table 1 Demographic, clinical, blood and urine biomarkers of the cohort: $n=178($ mean \pm SD $)$

\begin{tabular}{ll}
\hline Age & $\mathbf{7 6 . 1 \pm 8 . 2}$ \\
\hline Gender (ratio M:F) & $97: 81$ \\
\hline Education years & $10.9 \pm 2.1$ \\
\hline Duration of CKD & $5.9 \pm 3.5$ \\
\hline Duration of diabetes & $18.1 \pm 10.5$ \\
\hline History of ischaemic heart disease & $127(78 \%)$ \\
\hline History of hypertension & $161(90 \%)$ \\
\hline Systolic blood pressure (BP) mm Hg & $147.3 \pm 16.5$ \\
\hline Diastolic BP mm Hg & $76.7 \pm 8.5$ \\
\hline eGFR mL/min & $21.2 \pm 10.8$ \\
\hline Addenbrooke's cognitive assessment & $84.1 \pm 13.2$ \\
\hline Weigl Colour Form Sorting Test & $3.2 \pm 1.1$ \\
\hline PDQ-9 & $4.5 \pm 2.5$ \\
\hline EQ-5D & $0.69 \pm 0.15$ \\
\hline EQ-5D Visual Analogue Scale \% & $65.9 \pm 13.4$ \\
\hline Creatinine $\mu \mathrm{mol} / \mathrm{L}$ & $178.1 \pm 29.2$ \\
\hline HbA1c mmol/mol & $58.9 \pm 15.7$ \\
\hline Haemaglobin g/dL & $122.2 \pm 13.7$ \\
\hline Albumin (serum) g/L & $35.4 \pm 9.3$ \\
\hline Cholesterol mmol/L & $4.1 \pm 1.0$ \\
\hline HDL & $1.4 \pm 0.6$ \\
\hline LDL & $1.9 \pm 0.8$ \\
\hline Triglyceride mmol/L & $1.9 \pm 0.6$ \\
\hline
\end{tabular}

BP, blood pressure; CKD, chronic kidney disease; eGFR, estimated glomerular filtration rate.

results from this analysis are summarised with ORs and 95\% CIs. All analyses were performed using SPSS V.22 software. The level of significance was set at $\mathrm{p}<0.05 .{ }^{30}$

\section{RESULTS}

We recruited 185 subjects (98 male: 87 female) into the investigation, however, on review, seven patients were excluded from the analysis; three had a history of stroke, two had significant sensory impairments, one withdrew consent and the remaining patient had a severe neuropsychiatric disorder, leaving 178 cases (95 male: 83 female). The descriptive demographic, clinical and blood and urine biomarkers of the cohort are given in table 1.

\section{NCD outcomes and associations with the stage of CKD}

The cognitive assessment outcomes, diagnostic review and application of DSM- 5 criteria revealed, 86/178 (48\%) of the cohort had an NCD ranging from a mild NCD $(n=49)$, to a major NCD $(n=37)$. There were no cases of delirium observed at the time of testing. The frequencies and percentages of the cohort's NCD status by their stage of CKD are given in table 2. The diagnostic outcome review of the mild NCD group $(n=49)$, revealed eight patients with a single domain amnesic impairment and 26 with 
Table 2 Frequencies of neurocognitive diagnostic outcome and stage of chronic kidney disease

\begin{tabular}{|c|c|c|c|}
\hline & Stage 3a & Stage $3 b$ & Stage 3c \\
\hline & $(n=26)(\%)$ & $(n=69)(\%)$ & $(n=37)(\%)$ \\
\hline $\begin{array}{l}\text { No cognitive } \\
\text { impairment }(n=92)\end{array}$ & $11(12)$ & $40(43)$ & $41(45)$ \\
\hline $\begin{array}{l}\text { Mild neurocognitive } \\
\text { disorder (NCD) } \\
(n=49)\end{array}$ & $5(10)$ & $20(41)$ & $24(49)$ \\
\hline Major NCD $(n=37)$ & $10(27)$ & $9(24)$ & $18(49)$ \\
\hline
\end{tabular}

a multi domain cognitive impairment. The major NCD group $(n=37)$, had six with a possible Alzheimer's disease diagnosis, one with an NCD with Lewy bodies and a further two with an NCD due to Parkinson's disease. The remaining major NCD patients $(n=28)$ were coded as NCD due to other aetiologies.

In the current investigation, we did not find an association with the stage of CKD and executive, global or sub domain cognitive function ( $p=0.05$; online supplementary table 1). As expected, in all of the cognitive domains of the global (ACE III) and executive function (WCFST) assessments, significant differences were observed between the NCI, mild and major NCD groups $(\mathrm{p}<0001)$. A summary and a comparison between the neurocognitive assessment outcome and the cognitive subscales are presented in online supplementary table 2. To explore further the associations for worsening cognitive function between the NCI and mild MCI groups, a binary logistic regression was performed. The dependent variable set as the presence or absence of mild NCD and the independent variables of attention, memory, language, fluency, visuospatial and executive function, controlling for age, education (years), mood and gender were entered into a backward model. The logistic regression model indicated that there was a statistical association $\left(\chi^{2}(3)\right.$ $91.9, \mathrm{p}<0.0001)$ in the cognitive domains of attention, memory, fluency and executive function. This model explained $48.4 \%$ (Nagelkerke $\mathrm{R}^{2}$ ) of the variance with $88.5 \%$ cases correctly classified. Patients with mild NCD compared with those without cognitive impairment, more likely to have worse attention, (OR 1.9, 95\% CI 1.09 to 3.63 ), memory (OR $1.7,95 \%$ CI 1.37 to 2.09 ) and fluency (OR 1.8, 95\% CI 1.37 to 2.63). The analysis was repeated for the major NCD group which revealed a significant association $\left(\chi^{2}(3) 126.4, p<0.0001\right)$. This model explained $62.5 \%$ of the variance and correctly classified $97.40 \%$ of cases. This group had increased ORs for poorer cognitive function the domains of memory (1.6, $95 \%$ CI 1.89 to 2.69$)$, fluency $(2.08,95 \%$ CI 1.41 to 3.08$)$ and language $(1.67,95 \%$ CI 1.19 to 2.33$)$.

Significant age group differences between the NCI, patients with mild and major NCD were observed, $\mathrm{F}(2,175)=7.17, \mathrm{p}=0.01$ (table 3 ). Post hoc analysis established that the NCI group were significantly younger than major NCD group $(p=0.001)$, but not the mild NCD group $(\mathrm{p}=0.06)$. Age comparisons between the mild and major NCD groups did not reach significance $(\mathrm{p}=0.52)$. Overall there were significantly more males $(t=39.9, p<0.0001)$ in this investigation, however, this did not remain significant on analysis by neurocognitive subtype ( $\mathrm{p}=0.73$; table 3 ) . An exploration of mood (PDQ-9) indicted that there were significant differences between the three groups (NCI, mild NCD, major NCD), $F(2,175)=2.2, p=0.06$. The post hoc analysis (table 2) revealed that both the mild and major NCD groups reported significant worsening of mood compared with the NCI group $(\mathrm{p}<0.02 ; \mathrm{p}<0.04)$. The HRQol (EQ-5D; EQ-5D self-rating scale) among the three groups (NCI, mild and major NCD) differed significantly, $\quad \mathrm{F}(2,175)=3.67, \quad \mathrm{p}<0.027 ; \quad \mathrm{F}(2,175)=3.93$, $\mathrm{p}<0.021$ (table 3 ). However, on further analysis, only the mild NCD group were associated significantly poorer self-rated HRQoL ( $p>0.05$ ). To determine the if diabetic control was associated with NCD, analysis of HbAlc results found that both the mild and major NCD groups had significantly poorer diabetic control $(\mathrm{F}(5.33), \mathrm{p}<0.005$; table 3). To further explore this relationship, a binary logistic regression analysis was carried out by dichotomising patients with either normal or poor control of diabetes (HbAlc, <or $>42 \mathrm{mmol} / \mathrm{mol}$ ), with age, gender, stage of CKD, mood and CKD as covariates. On analysis, higher HbA1c in the mild and major NCD groups were found to be significantly associated with more attention deficits $(\mathrm{p}<0.02)$. Analysis of the remaining demographic, clinical, blood and markers, by neurocognitive diagnosis did not reveal any other significant associations (table 3).

\section{CKD stage and associations with the demographic, clinical,} blood and urine biomarkers

Of the 178 participants in this investigation, $83(46.6 \%)$ had severely reduced eGFR $(15-29 \mathrm{~mL} / \mathrm{min} / 1.732), 69$ $(38.8 \%)$ had a moderately reduced eGFR $(30-44 \mathrm{~mL} /$ $\min / 1.732)$ and $26(14.6)$ with a mildly reduced eGFR $(45-60 \mathrm{~mL} / \mathrm{min} / 1.732)$. The outcomes of the analysis are shown in table 4 . The mean eGFR $\leq 59 \mathrm{~mL} / \mathrm{min} / 1.73 \mathrm{~m}^{2}$ for the total cohort was 31.4 (11.5). As expected, lower eGFR, higher levels creatinine and a longer duration of CKD were significantly associated with the progression of CKD, $F(2,175)=246.14, p<0.0001$. There were significantly more males $(\mathrm{t}=38.9, \mathrm{p}<0.001)$, however, these differences did not remain when analysed by the stage of CKD ( $p=0.05)$. There were no significant differences observed with age, mood (PHQ-9), HRQoL (EQ-5D), education (years), blood pressure, by the stage of CKD. $\mathrm{Hb}$ concentration, controlling for age and gender was significantly associated with lower eGFR in the stage $3 \mathrm{~b}$ and 4 groups $(p<0.007$, table 4$)$. Controlling for anaemia within the $\mathrm{Hb}$ results, however did not reach significance $(\mathrm{p}=0.05)$. Blood and urine makers such as, albumin, urine albumin to creatinine ratio (ACR) and protein creatinine ratio (PCR) and lipid profiles by stage of CKD, controlling for by age and gender, revealed no significant differences $(p=0.05)$. 
Table 3 Demographic and clinical measures by neurocognitive assessment outcome (mean \pm SD)

\begin{tabular}{|c|c|c|c|c|}
\hline & \multirow{2}{*}{$\begin{array}{l}\mathrm{NCl} \\
(n=92)\end{array}$} & \multirow{2}{*}{$\begin{array}{l}\text { Mild NCD } \\
(n=49)\end{array}$} & \multirow{2}{*}{$\begin{array}{l}\text { Major NCD } \\
(n=37)\end{array}$} & \multirow{2}{*}{$\begin{array}{l}\text { P values } \\
\text { (Between-group differences) }\end{array}$} \\
\hline & & & & \\
\hline Age, years & $73.8 \pm 8.4^{*}$ & $77.4 \pm 8.6^{\star}$ & $79.2 \pm 5.4 \dagger$ & $0.001 \ddagger$ \\
\hline Education (years) & $11.2 \pm 2.1$ & $10.6 \pm 1.7$ & $10.9 \pm 3.5$ & $0.12^{\star \star}$ \\
\hline PDQ-9 & $3.9 \pm 2.4^{*}$ & $5.2 \pm 2.5^{\star}$ & $5.1 \pm 2.6^{*}$ & $0.006^{\star \star}$ \\
\hline EQ-5D Visual Analogue Scale: \% & $68.6 \pm 13.3^{\star^{-}}$ & $64.5 \pm 11.9^{*}$ & $62.5 \pm 14.2$ & $0.021^{\star *}$ \\
\hline Ischaemic heart disease & $64(69.5)$ & $35(71.4)$ & $28(75.6)$ & 0.26 \\
\hline Duration of diabetes (year) & $17.2 \pm(10.2)$ & $20.2 \pm(13.4)$ & $17.5 \pm(6.9)$ & $0.29 \ddagger$ \\
\hline Systolic BP mmol/L & $146.6 \pm 16.4$ & $147.3 \pm 18.2$ & $147.1 \pm 15.2$ & $0.65^{\star \star}$ \\
\hline Diastolic BP mmol/L & $75.5 \pm 8.1$ & $76.1 \pm 9.6$ & $79.8 \pm 7.8$ & $0.06^{\star \star}$ \\
\hline Creatinine $\mu \mathrm{mol} / \mathrm{L}$ & $180.7 \pm 62.1$ & $179.5 \pm 62.0$ & $163.6 \pm 48.2$ & $0.14^{\star \star}$ \\
\hline $\mathrm{HbA} 1 \mathrm{c} \mathrm{mmol} / \mathrm{mol}$ & $57.4 \pm 14.9^{\star} \dagger$ & $65.5 \pm 18.9^{*}$ & $55.4 \pm 11.3^{\star} \dagger$ & $0.005 \ddagger$ \\
\hline Haemaglobin $\mathrm{g} / \mathrm{dL}$ & $122.1 \pm 13.4$ & $122.6 \pm 14.8$ & $123.0 \pm 13.4$ & $0.89^{\star \star}$ \\
\hline Albumin (serum) $\mathrm{g} / \mathrm{L}$ & $36.5 \pm 12.4$ & $34.3 \pm 3.8$ & $34.6 \pm 2.9$ & $0.29^{\star *}$ \\
\hline Cholesterol mmol/L & $4.1 \pm 0.93$ & $4.4 \pm 1.2$ & $4.1 \pm 0.98$ & $0.19 \ddagger$ \\
\hline LDL mmol/L & $2.0 \pm 0.90$ & $2.3 \pm 1.1$ & $1.9 \pm 0.91$ & $0.20^{\star \star}$ \\
\hline HDL mmol/L & $1.4 \pm 0.51$ & $1.5 \pm 0.78$ & $1.3 \pm 0.44$ & $0.49^{\star \star}$ \\
\hline Triglyceride $\mathrm{mmol} / \mathrm{L}$ & $1.8 \pm 0.92$ & $1.9 \pm 1.1$ & $2.0 \pm 1.1$ & $0.38^{\star \star}$ \\
\hline
\end{tabular}

*Markers indicate significant differences between eGFR stages within the same row. For example, '2' indicates a difference from any other group stage on a particular row and ' 3 ' marked on a row are different from any other group not marked ' 3 '.

†Means across NCD stages are equal=null hypothesis.

$\ddagger$ Post hoc Games-Howell test calculated if Levene’s test of homogeneity was violated.

$\S \chi^{2}$ test.

${ }^{* \star} \mathrm{P}$ values calculated form analysis of variance $\mathrm{F}$ test, post hoc Tukey's HSD.

BP, blood pressure; CKD, chronic kidney disease; eGFR, estimated glomerular filtration rate; HSD, honestly significant difference; NCD, neurocognitive disorder; $\mathrm{NCl}$, no cognitive impairment.

\section{DISCUSSION}

To our knowledge, this is the first study in the UK to report that cognitive changes occur in a significant number of older adults with CKD and concomitant diabetes. We did not find an association with mild or major NCD by the stage of CKD. This study differs from previous investigations where we investigated the individual cognitive domains rather than analysing global cognitive scores alone. Furthermore, we also explored the relationship with the CKD stage and cognitive function.

This is the initial report from a prospective longitudinal investigation exploring the relationship with patients with NCD and CKD who at the time of assessment were not in ESKD failure, dialysis or a transplant recipient (eGFR, of $\leq 60 \mathrm{~m} \geq 15 \mathrm{~mL} / \mathrm{min} / 1.73 \mathrm{~m}^{2}$ ). The results here confirm that NCD is common in patients with moderate to advanced CKD and diabetes. The overall proportion of patients fulfilling DSM-5 criteria for an NCD being around $48 \%$ (mild $\mathrm{NCD}=49$; major $\mathrm{NCD}=37$ ). These findings support previous investigations into CKD and cognitive function. ${ }^{9}{ }^{10}$ However, the unexpected finding was that prior to cognitive assessment and application of DSM criteria, not any of the cohort had a diagnosis of an NCD. If patients with CDK are not diagnosed through life with an NCD, especially in view of the expected exponential rise of neurodegenerative disorders by the midpoint of this century, our findings suggest that current and future forecasts may significantly underestimate this cognitive burden worldwide.

An examination of the individual cognitive domain scores of the neuropsychological assessment employed in this investigation revealed that it was able to distinguish between patients with and without NCD. The strongest associations were found in the mild and major NCD groups in the cognitive domains of executive function, memory and fluency. It is, however, important to note that mild NCD (usually described as MCI), while a possible risk factor for the progression onto a major NCD, often remains stable, or patients revert to normal cognition. ${ }^{31}$ However, in other population and 
Table 4 Demographic and clinical measures by stage* of CKD

\begin{tabular}{|c|c|c|c|c|}
\hline & \multirow{2}{*}{$\begin{array}{l}\text { Stage 3a } \\
(n=26)\end{array}$} & \multirow{2}{*}{$\begin{array}{l}\text { Stage 3b } \\
(n=69)\end{array}$} & \multirow{2}{*}{$\begin{array}{l}\text { Stage } 4 \\
(n=83)\end{array}$} & \multirow{2}{*}{$\begin{array}{l}\text { P values } \\
\text { (Between group } \\
\text { differences)* }\end{array}$} \\
\hline & & & & \\
\hline Age, years & $74.8 \pm 8.2$ & $76.6 \pm 8.1$ & $75.9 \pm 8.2$ & $0.61 \dagger$ \\
\hline Gender (ratio M:F) & $51: 43$ & $29: 21$ & $18: 19$ & $0.23 \ddagger$ \\
\hline PHQ-9 & $4.9 \pm 2.6$ & $4.4 \pm 2.4$ & $4.8 \pm 2.3$ & $0.51 \dagger$ \\
\hline Duration education (year) & $10.3 \pm 1.69$ & $11.3 \pm 2.6 \rrbracket$ & $10.7 \pm 1.79$ & $0.08 \S$ \\
\hline$E Q-5 D$ & $0.68 \pm 0.19$ & $0.69 \pm 0.17$ & $0.69 \pm 0.15$ & $0.90 \dagger$ \\
\hline EQ-5D Visual Analogue Scale, \% & $66.1 \pm 14.4$ & $67.8 \pm 13.1$ & $64.4 \pm 13.2$ & $0.30 \dagger$ \\
\hline Duration of CKD (year) & $4.2 \pm 2.4 \rrbracket$ & $5.3 \pm 2.5$ ๆ & $6.9 \pm 4.19$ & $0.001 \dagger$ \\
\hline eGFR mL/min & $51.5 \pm 8.69$ & $34.2 \pm 5.6 \emptyset$ & $22.8 \pm 5.19$ & $0.001 \dagger$ \\
\hline Creatinine $\mu \mathrm{mol} / \mathrm{L}$ & $119.9 \pm 21.59$ & $160.3 \pm 39.6 \rrbracket$ & $210.9 \pm 60.79$ & $0.001 \S$ \\
\hline Ischaemic heart disease & $22(84.6)$ & $47(68.1 \%)$ & $58(69.9 \%)$ & $0.26 \ddagger$ \\
\hline Duration of diabetes (year) & $20.8 \pm 12.1$ & $16.9 \pm 8.7$ & $18.1 \pm 11.9$ & $0.34 †$ \\
\hline $\mathrm{HbA} 1 \mathrm{c} \mathrm{mmol} / \mathrm{mol}$ & $60.4 \pm 17.3$ & $60.8 \pm 14.9$ & $57.1 \pm 15.8$ & $0.3 \dagger$ \\
\hline Haemoglobin $\mathrm{g} / \mathrm{L}$ & $128.6 \pm 10.6 \rrbracket$ & $123.2 \pm 14.59$ & $119.3 \pm 13.29$ & $0.007 \dagger$ \\
\hline Albumin (serum) g/L & $38.6 \pm 16.6$ & $35.7 \pm 10.1$ & $34.2 \pm 3.9$ & $0.11 \dagger$ \\
\hline Urine ACR $\mathrm{mmol} / \mathrm{L}$ & 4.7 & 6.0 & 8.0 & $0.41^{* \star}$ \\
\hline Urine protein $\mathrm{CR} \mathrm{mmol} / \mathrm{L}$ & 33.0 & 30.0 & 40.5 & $0.26^{\star \star}$ \\
\hline Systolic BP mm Hg & $145.6 \pm 16.7$ & $146.4 \pm 18.5$ & $148.9 \pm 14.7$ & $0.49 \dagger$ \\
\hline Diastolic BP mm Hg & $79.1 \pm 7.3$ & $77.5 \pm 8.5$ & $75.3 \pm 16.5$ & $0.09 \dagger$ \\
\hline Cholesterol mmol/L & $4.2 \pm 1.3$ & $4.1 \pm 0.91$ & $4.1 \pm 1.1$ & $0.93 \dagger$ \\
\hline LDL mmol/L & $2.1 \pm 1.1$ & $2.0 \pm 0.82$ & $2.1 \pm 1.1$ & $0.87 \dagger$ \\
\hline $\mathrm{HDL} \mathrm{mmol/L}$ & $1.4 \pm 0.56$ & $1.4 \pm 0.48$ & $1.4 \pm 0.67$ & $0.89 \dagger$ \\
\hline Triglyceride $\mathrm{mmol} / \mathrm{L}$ & $2.1 \pm 0.89$ & $1.8 \pm 0.98$ & $1.9 \pm 1.1$ & $0.83 \dagger$ \\
\hline
\end{tabular}

Values for categorical values are given as percentages or ratios. Continuous variables are the mean \pm SD or median

${ }^{*}$ CKD Stage: 3a (Mild-Moderate): eGFR: 45-59: Stage 3b (Moderate-Severe): eGFR: 30-44: Stage 4 (Severe): eGFR: 15-29.

†P values calculated from analysis of variance $F$ test, post hoc Tukey's HSD.

$\ddagger P$ values calculated from $\chi^{2}$ test.

$\S$ Post hoc non-parametric Games-Howell test calculated if Levene's test of homogeneity was violated.

IMarkers indicate significant differences between eGFR stages within the same row. For example, '2' indicates a difference from any other group stage on a particular row and ' 3 ' marked on a row are different from any other group not marked ' 3 '.

${ }^{*} \mathrm{P}$ values calculated from Mood's median test.

BP, blood pressure; CKD, chronic kidney disease; eGFR, estimated glomerular filtration rate; HSD, honestly significant difference.

disease-specific conditions, MCI has been shown to be a significant predictor for the subsequent development of dementia. ${ }^{32} 33$ We suspect that MCI is fluctuant and in addition, the variability in the methodology and cognitive assessment in investigations will give rise to the inconsistency in reported outcomes. Further exploration in this area is warranted to establish the relationship with $\mathrm{CKD}$, MCI and its possible progression to major NCD.

Several investigations have reported that there is an association with declining kidney function and cognitive function in either the early or the end stage of the disease course. ${ }^{810}$ Whereas others have suggested that cognitive impairment is more likely to occur in the more advanced CKD stage $4(\mathrm{eGFR}<30) .{ }^{10}$ The current investigation in contrast found that NCD occurred with a similar frequency in all of the stages of CKD. Likewise, the duration CKD was not significantly associated with the degree of NCD within the cohort. The differences we observed may have arisen because we only assessed patients aged 55 years or more, those in the CKD stages $3 \mathrm{a}$, b and $4\left(\mathrm{eGFR} \leq 60 \mathrm{~m} \geq 15 \mathrm{~m} \mathrm{~L} / \mathrm{min} / 1.73 \mathrm{~m}^{2}\right)$, and with an additional diagnosis of diabetes mellitus. Previous investigations have included patients from an eGFR of $\geq 90$ with presumably less comorbid disease, through to end-stage CKD (eGFR of $<15$ ), including those in receipt of renal replacement therapy or post-transplantation. However, the Chronic Renal Insufficiency Cohort (CRIC), as we found have recently reported that the stage of CKD is not a necessarily a predictor for the development of cognitive impairment. $^{9}$

Other risk factors including vascular disease and diabetes are frequently reported comorbid conditions associated with $\mathrm{CKD}$. The prevalence of lower $\mathrm{Hb}$ concentration in general and CKD population investigations has 
been shown to be associated with impaired cognitive function. ${ }^{34} 35$ Anaemia in CKD is common, particularly as kidney function declines and in the current study over $60 \%$ of the cohort had $\mathrm{Hb}$ concentrations falling into the anaemic range. However, we found no association with the stage of $\mathrm{CKD}$, cognitive function and $\mathrm{Hb}$ concentrations. The recent report from the CRIC study group similarly reported no association in patients with CKD with anaemia and cognitive function. ${ }^{36}$ Diabetes mellitus is also thought to contribute to the development of cognitive impairment and dementia. ${ }^{37} 38$ This is thought to be as a result of the increased vascular disease risk, its association with amyloid metabolism and blood glucose levels. Some investigations have reported that poor diabetic control is associated with impairments in the cognitive domains of executive function, memory and global function. ${ }^{39}{ }^{40}$ Although the current investigation found a weak predictive association with attention deficits and increasing HbAlc, no other associations with cognitive function were observed in this investigation. This perhaps is due to the established or increased cardiovascular risk factors, where, for instance, they had a diagnosis of diabetes mellitus, $80 \%$ had a history of hypertension and a significant proportion had ischaemic heart disease. It has been suggested that multifactorial clinical and societal and potentially modifiable risk factors, such as reductions in the incidence of diabetes, obesity, may contribute equally if not more than genetic risks such as Apolipoprotein $\mathrm{E} 4$ allele (ApoE) status alone for dementia. ${ }^{41} 42$ It is possible then that CKD may not be a causative risk per se, but instead the established comorbid risk factors associated with CKD, contribute to an increased likelihood that these patients have a lifetime developmental risk for an NCD. More incident population longitudinal investigations with matched controls controlling for these covariates are needed to resolve this.

The most recent version of DSM has replaced the term dementia with mild and major NCD, because it was felt to be less stigmatising for patients and families. It also allowed for more flexible diagnostic criteria, assisting clinicians in making a decision on the severity of decreased mental or cognitive impairment in patients. The difficulty we found with DSM-5 was that while the most common NCD such as Alzheimer's, Parkinson's, vascular, HIV infection have specific categories, CKD does not. Although the current investigation was able to specify major NCD in $9(32 \%)$ cases, the majority fell into DSM-5 category 'due to other aetiologies'. We did consider possible vascular NCD in significant a number of these patients because of their existing comorbid risk factors for vascular disease as described earlier. The DSM-5 criterion for probable or possible vascular NCD, however, requires evidence of one or more cerebrovascular event, with additional supporting neuroimaging where possible. However, the exclusion criterion in the current study was the history of a stroke or TIA and along with a lack of neuroimaging data makes it difficult to attribute their NCD to vascular disease. We feel that this is potentially a weakness of the current DSM and should be addressed in subsequent revisions of the criteria to include CKD and its association with possible an probable vascular risks and NCD.

The current investigation does have several limitations. We lacked information on other variables such as, neuroimaging to confirm or support cardiovascular diagnosis and ApoE risk status. We employed one executive function assessment and a single multiple cognitive domain neuropsychological assessment. Although more comprehensive multiple assessments may have yielded stronger associations with CKD and cognitive function, the individual analysis of the global assessment was sensitive enough to discriminate between the NCD groups. The participants in this investigation are not necessarily representative of all patients with CKD because we first restricted our recruitment to those with and additional diagnosis of diabetes mellitus Second, the cohort was a cross-sectional population with multiple comorbidities who were at risk of developing cognitive impairment. Lastly, the current investigation lacked a disease-free comparison group. To address these methodological issues, we are currently recruiting and assessing an incident CKD cohort with and without diabetes, along with an age-matched and gendermatched healthy control cohort.

\section{CONCLUSIONS}

Cognitive function is often not routinely assessed as part of the clinical management in CKD, despite the known association with worsening renal function and ageing. The current UK National Institute for Health and Care Excellence guidance does not address cognitive function in the assessment and management of CKD and we would recommend that this is addressed in subsequent revisions. ${ }^{43}$ Our findings also suggest that the cognitive function of patients with CKD should be screened and monitored routinely. In addition, an agreed set of cognitive assessment battery should be established to allow for data sharing and national and international comparisons.

Acknowledgements This study was presented as a poster at the International Congress of the European Geriatric Society, Berlin, Germany, 2018. Eur. Geriatr Med (2018) 9 (Suppl 1): S321: https://doi.org/10.1007/s41999-018-0097-4.

Contributors PH and MK conceived and designed the study, collected the data and managed the database. PH and MK contributed to data cleaning and performed the statistical analyses. PH, AL, HN, SW and MK contributed to interpretation of the data. PH, AL, HN, SW and MK wrote the manuscript. All authors critically reviewed the manuscript and approved the final version to be published.

Funding The authors have not declared a specific grant for this research from any funding agency in the public, commercial or not-for-profit sectors.

Competing interests None declared.

Patient consent Not required.

Ethics approval Approval was given by the Central Research and Ethics committee, North Wales.

Provenance and peer review Not commissioned; externally peer reviewed.

Data sharing statement № additional data are available.

Open access This is an open access article distributed in accordance with the Creative Commons Attribution Non Commercial (CC BY-NC 4.0) license, which permits others to distribute, remix, adapt, build upon this work non-commercially, 
and license their derivative works on different terms, provided the original work is properly cited, appropriate credit is given, any changes made indicated, and the use is non-commercial. See: http://creativecommons.org/licenses/by-nc/4.0/.

\section{REFERENCES}

1. Hedgeman E, Lipworth L, Lowe K, et al. International burden of chronic kidney disease and secondary hyperparathyroidism: a systematic review of the literature and available data. Int J Nephrol 2015;2015:1-15.

2. Zhang QL, Rothenbacher D. Prevalence of chronic kidney disease in population-based studies: systematic review. BMC Public Health 2008;8:117.

3. Bailie GR, Uhlig K, Levey AS. Clinical practice guidelines in nephrology: evaluation, classification, and stratification of chronic kidney disease. Pharmacotherapy 2005;25:491-502.

4. Parikh NI, Hwang SJ, Larson MG, et al. Chronic kidney disease as a predictor of cardiovascular disease (from the Framingham Heart Study). Am J Cardiol 2008;102:47-53.

5. Kurella M, Chertow GM, Luan J, et al. Cognitive impairment in chronic kidney disease. J Am Geriatr Soc 2004;52:1863-9.

6. Murray AM, Tupper DE, Knopman DS, et al. Cognitive impairment in hemodialysis patients is common. Neurology 2006;67:216-23.

7. Khatri M, Nickolas T, Moon YP, et al. CKD associates with cognitive decline. J Am Soc Nephrol 2009;20:2427-32.

8. Etgen T, Chonchol M, Förstl H, et al. Chronic kidney disease and cognitive impairment: a systematic review and meta-analysis. Am J Nephrol 2012;35:474-82.

9. Kurella Tamura M, Yaffe K, Hsu CY, et al. Cognitive impairment and progression of CKD. Am J Kidney Dis 2016;68:77-83.

10. Berger I, Wu S, Masson P, et al. Cognition in chronic kidney disease: a systematic review and meta-analysis. BMC Med 2016;14:206.

11. Etgen T, Sander D, Chonchol M, et al. Chronic kidney disease is associated with incident cognitive impairment in the elderly: the INVADE study. Nephrol Dial Transplant 2009;24:3144-50.

12. Murray AM, Bell EJ, Tupper DE, et al. The Brain in Kidney Disease (BRINK) Cohort Study: Design and Baseline Cognitive Function. Am J Kidney Dis 2016;67:593-600.

13. Griva K, Stygall J, Hankins M, et al. Cognitive impairment and 7-year mortality in dialysis patients. Am J Kidney Dis 2010;56:693-703.

14. Rocca WA, Petersen RC, Knopman DS, et al. Trends in the incidence and prevalence of Alzheimer's disease, dementia, and cognitive impairment in the United States. Alzheimers Dement 2011;7:80-93.

15. Schrijvers EM, Verhaaren BF, Koudstaal PJ, et al. Is dementia incidence declining?: trends in dementia incidence since 1990 in the rotterdam study. Neurology 2012;78:1456-63.

16. Matthews FE, Arthur A, Barnes LE, et al. A two-decade comparison of prevalence of dementia in individuals aged 65 years and older from three geographical areas of England: results of the Cognitive Function and Ageing Study I and II. Lancet 2013;382:1405-12.

17. Qiu C, von Strauss E, Bäckman L, et al. Twenty-year changes in dementia occurrence suggest decreasing incidence in central Stockholm, Sweden. Neurology 2013;80:1888-94.

18. Satizabal CL, Beiser AS, Chouraki V, et al. Incidence of dementia over three decades in the framingham heart study. $N$ Engl $\mathrm{J} \mathrm{Med}$ 2016;374:523-32.

19. Barnes DE, Yaffe K. The projected effect of risk factor reduction on Alzheimer's disease prevalence. Lancet Neurol 2011;10:819-28.

20. Deckers K, van Boxtel MP, Schiepers OJ, et al. Target risk factors for dementia prevention: a systematic review and Delphi consensus study on the evidence from observational studies. Int $J$ Geriatr Psychiatry 2015;30:234-46.

21. Chronic Kidney Disease: Early identification and management of chronic kidney disease in adults in primary and secondary care. NICE Clinical Guideline 2008;73.
22. Hsieh S, Schubert S, Hoon C, et al. Validation of the addenbrooke's cognitive examination iii in frontotemporal dementia and alzheimer's disease. Dement Geriatr Cogn Disord 2013;36:242-50.

23. Hobson P, Meara J, Taylor C. The weigl colour-form sorting test: a quick and easily administered bedside screen for dementia and executive dysfunction. Int J Geriatr Psychiatry 2007;22:909-15.

24. American Psychiatric Association. Diagnostic and statistical manual of mental disorders. 5th edn. Washington DC: American Psychiatric Association, 2013

25. Petersen RC, Doody R, Kurz A, et al. Current concepts in mild cognitive impairment. Arch Neurol 2001;58:1985-92.

26. Petersen RC. Mild Cognitive Impairment. N Engl J Med Overseas Ed 2011;364:2227-34.

27. Kroenke K, Spitzer RL, Williams JB. The PHQ-9: validity of a brief depression severity measure. J Gen Intern Med 2001;16:606-13.

28. Williams A. EuroQol Group. EuroQol-a new facility for the measurement of health-related quality of life. Health Policy 1990;16:199-208.

29. DeMaeyer $\mathrm{E}$, Adiels-Tegman M. The prevalence of anaemia in the world. World Health Stat Q 1985;38:302-16.

30. IBM CR. IBM SPSS Statistics for Windows, Version 22.0. Armonk, NY: IBM Corp, 2013.

31. Pandya SY, Clem MA, Silva LM, et al. Does mild cognitive impairment always lead to dementia? A review. J Neurol Sci 2016;369:57-62.

32. Staekenborg SS, Koedam EL, Henneman WJ, et al. Progression of mild cognitive impairment to dementia: contribution of cerebrovascular disease compared with medial temporal lobe atrophy. Stroke 2009;40:1269-74.

33. Hobson P, Meara J. Mild cognitive impairment in parkinson's disease and its progression onto dementia: a 16-year outcome evaluation of the denbighshire cohort. Int J Geriatr Psychiatry 2015;30:1048-55.

34. Hong $\mathrm{CH}$, Falvey $\mathrm{C}$, Harris TB, et al. Anemia and risk of dementia in older adults: findings from the Health $\mathrm{ABC}$ study. Neurology 2013;81:528-33.

35. Kurella Tamura M, Xie D, Yaffe K, et al. Vascular risk factors and cognitive impairment in chronic kidney disease: the Chronic Renal Insufficiency Cohort (CRIC) study. Clin J Am Soc Nephrol 2011;6:248-56.

36. Kurella Tamura M, Vittinghoff E, Yang J, et al. Anemia and risk for cognitive decline in chronic kidney disease. BMC Nephrol 2016;17:13

37. NCD Risk Factor Collaboration (NCD-RisC). Worldwide trends in diabetes since 1980: a pooled analysis of 751 population-based studies with 4.4 million participants. Lancet 2016;387:1513-30.

38. Zheng F, Yan L, Yang Z, et al. $\mathrm{HbA}_{1}$, diabetes and cognitive decline: the english longitudinal study of ageing. Diabetologia 2018;61:839-48.

39. Rawlings AM, Sharrett AR, Schneider AL, et al. Diabetes in midlife and cognitive change over 20 years: a cohort study. Ann Intern Med 2014:161:785-93.

40. Tuligenga RH, Dugravot A, Tabák AG, et al. Midlife type 2 diabetes and poor glycaemic control as risk factors for cognitive decline in early old age: a post-hoc analysis of the Whitehall II cohort study. Lancet Diabetes Endocrinol 2014;2:228-35.

41. Ashby-Mitchell K, Burns R, Shaw J, et al. Proportion of dementia in Australia explained by common modifiable risk factors. Alzheimers Res Ther 2017;9:11.

42. Rakesh G, Szabo ST, Alexopoulos GS, et al. Strategies for dementia prevention: latest evidence and implications. Ther Adv Chronic Dis 2017;8:121-36.

43. National Clinical Guideline Centre. Chronic kidney disease: national clinical guideline for early identification and management in adults in primary and secondary care (update): National Institute for Health and Care Excellence, 2014. 